\section{Protozoa with lashes}

The Ciliates. By A. R. Jones. Pp. 207. (Hutchinson: London, April 1974.) $£ 3.50$ boards; $£ 2$ paper.

My first impressions of this little book were similar to those of a research student who, in the local bookshop, announced that it looked dull and uninteresting. But first impressions can be misleading and I subsequently discovered the written content to be of a better quality than the visual appeal.

The subject matter of the book is wide including chapters on the form, fine structure, locomotion, feeding, nutrition, reproduction, growth, taxonomy, and economic importance of ciliated protoza. In general these chapters are readable, interesting and up to date although in places the style is rather slack. A complete chapter devoted to osmoregulation and ion control is a refreshing feature not usually included in such textbooks and reflects the personal interests of Dr Jones. The book is obviously written with some enthusiasm for the subject and I found several pieces of new and useful information not included in other texts. I am not enthusiastic about the general format of this series of books and in this one I would have liked to have seen more original illustrations. In several places I felt that a good diagram would have made the description simpler and more concise.

As in all modern textbooks there is the inevitable series of errors scattered throughout the text. Some although minor could be misleading, for example, referring to the Ciliophora as a subphylum and a class on the same page, the invention of a new genus Campanula (for Campanella) and some erroneous references. Although I remain unclear at whom the book is really aimed I can recommend it to all those interested in ciliates since it does make a useful addition to the small but rapidly growing set of books dedicated to protozoological topics. COLIN R. Curds

\section{Dying of cold}

Temperature and Life. By H. Precht, J. Christophersen, H. Hensel and W. Larcher. Pp. $\mathbf{x x}+779$. (SpringerVerlag: Berlin and New York, 1974.) DM 142; $\$ 58.30$.

Effects of Temperature on Ectothermic Organisms: Ecological Implications and Mechanisms of Compensation. Edited by Wolfgang Weiser. Pp. xi+298. (Springer-Verlag: Berlin and New York, 1974.) DM 66; \$23.10.

Temperature is one of the most important and easily measured environmental infuences affecting living organisms. Many aspects of physiology are best understood in terms of reactions to stress and, of the various factors causing stress, temperature is, perhaps, the one most often encountered. Study of thermoregulation has contributed much to the concept of control theory in biology: by the same token, investigation of thermal adjustment in ectothermal animals is likely to have far-reaching influence on ideas about the regulation of metabolism in general. For reasons such as these, various aspects of thermobiology are today being studied extensively, with the result that new books and review articles are constantly appearing. The volumes under review are the latest on the subject to appear.

The first is a revised and updated English version of Temperatur und Leben by Precht, Christophersen and Hensel, first published in 1955. Although constructed along the same lines as its predecessor, it differs in that the number of contributors has been increased to include two microbiologists, one biochemist, seven botanists, three zoophysiologists and three human physiologists. An attempt is made to treat as many problems as possible, but the main theme remains the adaptation of organisms to changing temperatures. A supplementary volume on physical and chemical aspects by $L$. Lumper, is to be published later. A special effort has avowedly been made to cover, often in the form of footnotes, the copious literature that has appeared since 1955 . To judge by those particular fields with which I am familiar, however, it would seem unlikely that more than about one tenth, at most, of significant contributions has been included. Even so, a rather turgid compendium has been produced, probably of use to research workers for reference purposes rather than for stimulation, whose detail at the same time far exceeds the requirements of most graduate students.

The various chapters have been grouped under the headings of poikilothermic organisms (microorganisms, plants, animals) and homeothermic organisms. In my view there is no clear distinction between homeothermy and poikilothermy, so the classification adopted tends to obscure the relationship between homeothermy and size in animals. With an unfavourable surface to volume ratio, the maintenance of a constant body temperature would be economically unacceptable for small organisms.

Temperature and Life shows little evidence of the meticulous planning that clearly went into its nearest competitors such as: Temperature Regulation in Mammals and other Vertebrates by J. Bligh, (Elsevier, North-Holland: Amsterdam, 1973): Cryobiology cdited by H. T. Merryman (Academic Press:
London and New York, 1966); Thermobiology edited by A. H. Rose (Academic Press: London and New York, 1967); and Comparative Physiology of Thermoregulation, vols 1-3, edited by G. C. Whittow (Academic Press: New York and London, 1970, 71, 73). Of course, none of these covers quite such a wide field as the new book, although their design is far better. Indeed, herein lies the nub of my criticism. The study of temperature and life has long since passed the point at which it can be reviewed comprehensively in a single volume-even one of 779 pages with fine type.

Wolfgang Wieser's book likewise suffers from the fact that it possesses little intrinstic homogeneity. This, however, is probably unavoidable, since it represents the proceedings of a symposium held at Obergurgl, Austria, from September 4-8, 1972, at which only a restricted number of topics was covered. The 25 contributions are grouped under three headings: mechanisms, ecology and cold resistance but, within these broad classifications there is often little in common between one paper and the next. There is also very considerable variation in quality. An opening review by the editor stresses the complex "multistable system" from which the answer best suited to the prevailing or anticipated thermal régime is called into action by changes in ambient temperature. This farsighted approach may well provide the kind of stimulus lacking from Temperature and Life.

Despite the vast amount of data reviewed in both books, it is evident that knowledge of thermobiology is still superficial. To cite a few examples, the mechanisms by which death results from heat or cold are very imperfectly understood. They are certainly diverse and are complicated by the fact that unrelated mechanisms within an organism may be influenced concurrently in different ways. Extremes of temperature may denature enzymes, or liquify membrane lipids. The injurious action of heat may also damage mitochondria, affect the coding of proteins, impair the coordination of physiological processes, disturb the functioning of endocrine glands and neurosecretion, and engender the accumulation of harmful metabolic products or an inadequacy in the transport and supply of oxygen. The harmful effects of cold are equally multiple. Again, little is known of the neurophysiology or mode of function of thermal receptors in animals, nor why long-term adaptation has so little effect on the properties of these sense organs. It would be misleading to lump together a number of unrelated phenomena merely because they are engendered by the same thermat influence: one must therefore accept the fact that no unitary explanation exists. 